Original Research Article

\title{
The prescribing pattern for the management of dengue fever in pediatric patients of a tertiary care hospital: an observational study
}

\author{
Shruthi Rammohan ${ }^{1 *}$, Basavaraj Bhandare ${ }^{1}$, Adarsh E. ${ }^{2}$, Satyanarayana V. ${ }^{1}$
}

\begin{abstract}
${ }^{1}$ Department of Pharmacology, ${ }^{2}$ Department of Paediatrics, RajaRajeswari Medical College and Hospital, Bangalore, Karnataka, India
\end{abstract}

Received: 24 September 2018 Accepted: 22 October 2018

\section{*Correspondence to: Dr. Shruthi Rammohan, Email: shruthi.r.mohan@ gmail.com}

Copyright: (C) the author(s), publisher and licensee Medip Academy. This is an openaccess article distributed under the terms of the Creative Commons Attribution NonCommercial License, which permits unrestricted noncommercial use, distribution, and reproduction in any medium, provided the original work is properly cited.

\begin{abstract}
Background: Dengue fever is a mosquito borne viral infection which has become a global health hazard, especially in tropical and subtropical areas. Children have higher risk of developing severe forms of dengue fever, however, studies show that paediatric complications/fatalities from dengue fever are potentially avoidable by proper management. Data about drug usage patterns for dengue are particularly lacking, especially in the paediatric age group, therefore this study will help facilitate the rational use of drugs and aid in establishing a more specific management for dengue fever. The objective of the present study was to identify the prescribing pattern of dengue fever in paediatric inpatients admitted to RajaRajeswari Medical College and Hospital and assess according to the WHO core prescribing indicators

Methods: This prospective observational study took place from March 2017 to September 2017 in the paediatric general wards. Data was collected from case files of NS1 positive patients of both genders between 1-18years. Data was analysed using descriptive statistics and expressed as percentages, means and standard deviations. The prescription pattern was analysed using the prescribing indicators mentioned in the World Health Organization core drug use indicators. Results: Total of 300 drugs were prescribed for 110 prescriptions that were analysed excluding IV fluids and blood products. Mean number of drugs prescribed was $2.7 \pm 0.8$. Drugs prescribed by a generic name was $7.33 \%$. Patients prescribed an antibiotic was $12.73 \%$. Patients prescribed with an injection was $62.72 \%$ Majority of drugs prescribed in this study come from essential medicines list created by regulatory bodies. Intravenous fluids were administered to all patients with majority receiving normal saline $(60.9 \%)$.

Conclusions: Mainstay of treatment of dengue fever for paediatric patients is symptomatic along with focus on fluid management. Majority of drugs prescribed are from essential medicines lists formed by regulatory bodies. With dengue infections being a worldwide health hazard, more studies are needed to facilitate rational use of drugs in this disease.
\end{abstract}

Keywords: Dengue fever, Prescribing pattern, Paediatrics, Rational prescribing

\section{INTRODUCTION}

Dengue fever (DF) is a mosquito transmitted viral infection that has become a worldwide health hazard, especially in tropical and subtropical countries. ${ }^{1,2}$ According to the World Health Organization (WHO), the recent estimate indicates 390 million dengue infections occurring each year. India is one of the South-East Asian countries repeatedly reporting incidences of DF. ${ }^{3}$ In India, DF has been an endemic for over two centuries, especially in the states of Delhi, Rajasthan, Haryana, Punjab, Maharashtra, Karnataka, Tamil Nadu and Pondicherry., In Karnataka the Directorate of National Vector Borne Disease Control Programme has reported 4,186 cases till July $30^{\text {th }}, 2017$. 
Dengue viruses are arboviruses belonging to the Flaviviridae family which are transmitted by the Aedes mosquito. ${ }^{2}$ There are four distinct serotypes which include DENV-1, DENV-2, DENV-3, and DENV-4.2 All four serotypes can produce the full spectrum of the disease. The various presentations may be of a subclinical infection, dengue fever (DF) which is a mild self-limiting disease, or a severe disease with fatal complications known as dengue hemorrhagic fever/dengue shock syndrome (DHF/DSS). ${ }^{6}$ Patients present with varied symptomatology including onset of high fever with chills, severe retro-orbital headache, myalgia, arthralgia, rashes, loss of appetite, nausea and vomiting. ${ }^{1}$

In South East Asian countries like India, DF is a major health problem affecting the paediatric age group. ${ }^{7}$ This is due to rapid urbanization with unplanned construction activities and poor sanitation which contributes to fertile breeding grounds for mosquitoes. ${ }^{3}$ Children are at a higher risk of developing severe forms of DF. Epidemiological studies conducted in India show severe dengue to be predominantly seen in children. Other studies have shown that paediatric deaths due to complications of dengue are potentially avoidable by proper management. ${ }^{8}$

There is no specific treatment or antiviral therapy for dengue infections and WHO states that the management of dengue should be symptomatic and supportive. ${ }^{9}$ The mainstay of therapy is focussed on fluid management in order to avoid dehydration and its complications. Other symptoms are managed as needed. ${ }^{10}$ Blood products may be needed in patients having a serum platelet level $<20,000 / \mu 1$ with profuse bleeding complications however, the benefits of transfusing are controversial among attending physicians. ${ }^{11}$

Studies on prescription patterns aids in the rational use of drugs in various populations. ${ }^{9}$ Assessment of drug usage patterns using the WHO core drug use indicators is very much needed in order to promote rational drug use, especially in developing countries. ${ }^{12}$ Data about the drug usage patterns in DF are particularly lacking, especially in the paediatric age group. ${ }^{5}$ Hence this study was undertaken with the aim of identifying the pattern of drugs prescribed in the management of dengue fever in paediatric inpatients of RajaRajeswari Medical College and Hospital (RRMCH) and assess according to the WHO core drug use indicators to further facilitate the rational use of drugs used and establish a more specific treatment for dengue fever.

\section{METHODS}

This study is a prospective observational study which was carried out among the in-patients admitted to the paediatric general wards of RRMCH, a tertiary care hospital in Bangalore, Karnataka, India. Approval from the institutional ethics committee was obtained prior to commencement. The study period was for a duration of 6 months from $1^{\text {st }}$ March 2017 to $30^{\text {th }}$ September 2017 in which data was collected from the case files of patients admitted during that time. The cases which were included in this study were both male and female patients who were between the ages of 1-18years having a confirmed NS1 positive status. Informed consent was also taken by the patient or parent/guardian. The cases that were excluded from this study were patients who had a suspected diagnosis of dengue fever but was determined to have an NS1 negative status or those patients who were having any comorbidities like asthma, diabetes, genetic disorders, haematological disorders or any co-infections.

The data obtained was collected according to a standard proforma which included demographic details (name, hospital in-patient number, age, sex and duration of hospital stay) and drug details (drug name, generic or brand name, dose, duration, frequency and route of administration). The type of IV fluid given and administration of platelet transfusions were also noted in the proforma. All the data was entered into MS Excel and was analysed as per the WHO core drug use indicators using descriptive statistics expressed as percentages, mean and standard deviation (SD).

There are 5 core drug use indicators which are: the average number of drugs per prescription, the percentage of drugs prescribed by a generic name, the percentage of encounters with an antibiotic prescribed, the percentage of encounters prescribed with an injectable drug and the percentage of drugs prescribed from an essential medicines list. In this study, two lists were taken into consideration: the WHO $20^{\text {th }}$ Essential Medicines List 2017 and the National List of Essential Medicines of India 2015. IV fluids and platelet transfusions were analysed separately.

\section{RESULTS}

A total of 300 drugs were prescribed from the 110 prescriptions that were included in this study during the study period. All the cases included had a confirmed diagnosis of DF with a positive NS1 status. The age range included cases from 1 to 18 years (Figure 1 ). The majority of cases were from the 6-10years (33.6\%) and 11-15 years $(33.6 \%)$ age group. A female predominance was seen with $55.5 \%$ females and $44.5 \%$ males (Figure 2 ). The mean age was comparable in both genders (Table 1).

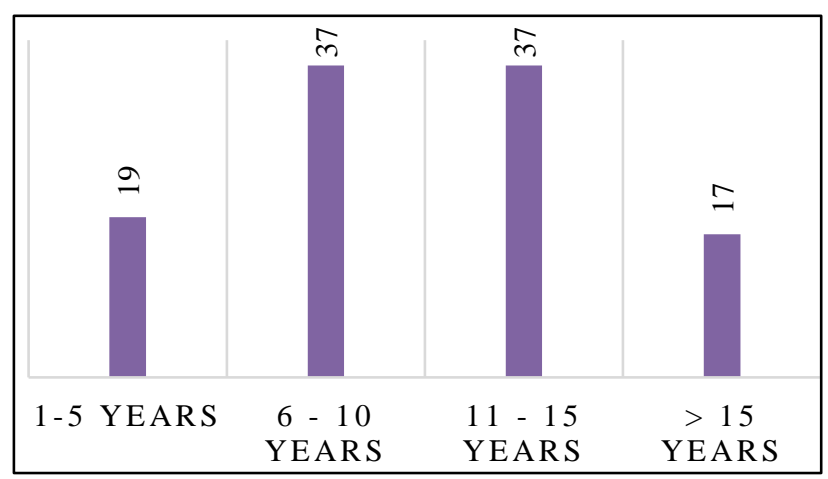

Figure 1: Age distribution of study population. 
Table 1: Demographic parameters.

\begin{tabular}{|ll|}
\hline Demographic data & Values \\
\hline Age & \\
\hline $1-5$ years & $19 / 110(17.3 \%)$ \\
\hline $6-10$ years & $37 / 110(33.6 \%)$ \\
\hline $11-15$ years & $37 / 110(33.6 \%)$ \\
\hline$>15$ years & $17 / 110(15.5 \%)$ \\
\hline Sex & $49 / 110(44.5 \%)$ \\
\hline Male & $61 / 110(55.5 \%)$ \\
\hline Female & $100 \%$ \\
\hline Other parameters & $10.5 \pm 4.2$ \\
\hline NS1 positive & $10.3 \pm 4.3$ \\
\hline Mean age in males & $4.2 \pm 1.2$ \\
\hline Mean age in females & \\
\hline Mean duration of stay & \\
\hline
\end{tabular}

Treatment administered were antipyretics (90\%), antiulcer agents (88.18\%), antiemetics (70\%), antibiotics (12.73\%) and miscellaneous drugs (11.82\%) (Table 2, Figure 3) All patients received IV fluids with majority receiving normal saline (60.9\%) compared to Ringer's lactate (39.1\%). (Figure 4) The antipyretic administered was paracetamol (33\%). Antiulcer agents prescribed included pantoprazole $(22.3 \%)$ mostly and lansoprazole (10.3\%). Ondansetron $(25.3 \%)$ was the antiemetic given. Patients given antibiotics included doxycycline (1\%), ceftriaxone $(1.7 \%)$, amoxicillin-clavulanate $(1 \%)$ or amikacin $(1 \%)$. Miscellaneous drugs which were administered to few patients included zinc, vitamin c, mefenamic acid, lactic acid bacillus, etc. Of the 110 patients, 4 (3.6\%) were administered platelet transfusion.

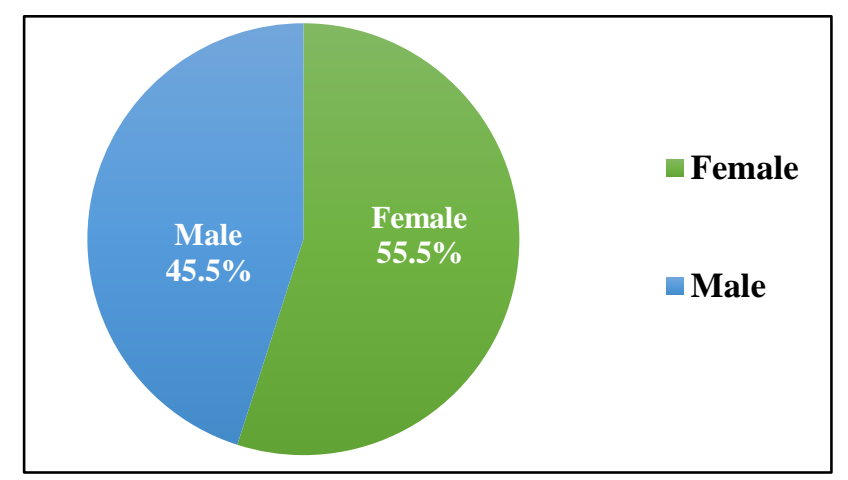

Figure 2: Gender distribution of study population.

Table 2: Frequency and percentage of cases with the prescribed class of drugs.

\begin{tabular}{|ll|l|}
\hline Class of drugs & Frequency & Percentage \\
\hline IV Fluids & $110 / 110$ & $100 \%$ \\
\hline Antipyretics & $99 / 110$ & $90 \%$ \\
\hline Antiulcer & $97 / 110$ & $88.18 \%$ \\
\hline Antiemetic & $77 / 110$ & $70 \%$ \\
\hline Antibiotic & $14 / 110$ & $12.73 \%$ \\
\hline Miscellaneous & $13 / 110$ & $11.82 \%$ \\
\hline Platelet transfusion & $4 / 110$ & $3.6 \%$ \\
\hline
\end{tabular}

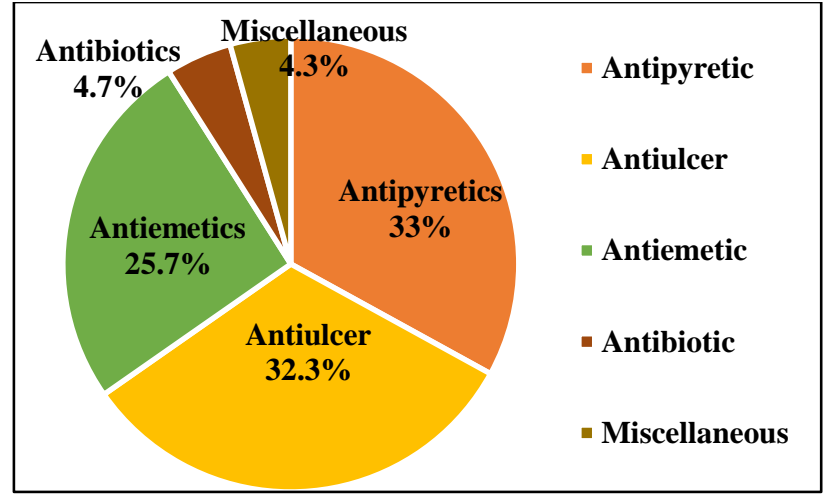

Figure 3: Percentages of drug class prescribed from total number of drugs.

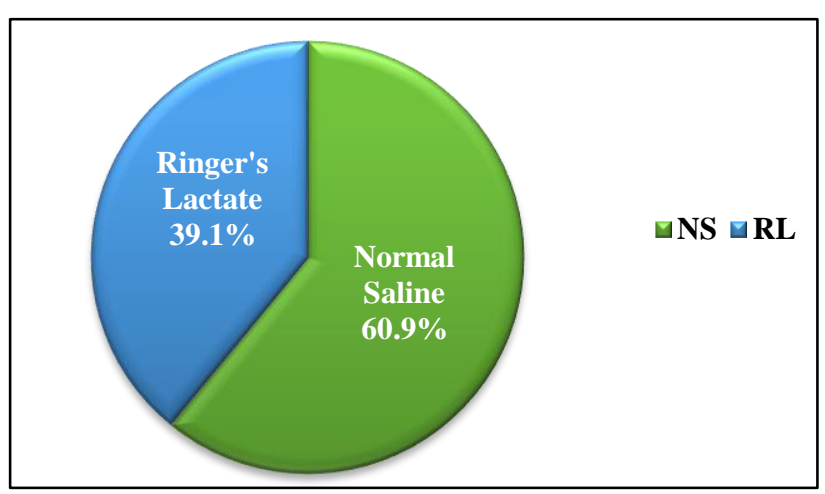

Figure 4: Percentage of IV fluids used.

Table 3: Number of cases with the prescribed number of drugs.

\begin{tabular}{|l|l|}
\hline C & No. of patients \\
\hline 1 & 2 \\
\hline 2 & 43 \\
\hline 3 & 54 \\
\hline 4 & 6 \\
\hline 5 & 4 \\
\hline 6 & 1 \\
\hline Total & 110 \\
\hline Mean \pm SD & $2.7 \pm 0.8$ \\
\hline
\end{tabular}

As per the analysis according to the WHO core drug use indicators, the following results were obtained. The majority of patients were prescribed a total of 3 drugs and the average number of drugs prescribed was $2.7 \pm 0.8$. (Table 3). The percentage of drugs that were prescribed by a generic name was $7.33 \%$. The percentage of encounters which had an antibiotic prescribed was $12.73 \%$. The percentage of encounters which had a drug prescribed by the parenteral route was $62.72 \%$. Lastly, with regards to drugs prescribed from an essential medicines list, we took two lists into consideration. Of the 300 drugs prescribed, $200(66.7 \%)$ were on the $20^{\text {th }}$ essential medicines list 2017 by WHO and $265(88.3 \%)$ were on the national list of essential medicines 2015 (Table 4). 
Table 4: WHO core drug use indicators.

\begin{tabular}{|c|c|c|}
\hline Indicator & Mean \pm SD & \\
\hline Average number of drugs per encounter & $2.7 \pm 0.8$ & \\
\hline Indicator & Percentage & No. / Total \\
\hline Percentage of drugs prescribed by generic name & $7.33 \%$ & $22 / 300$ \\
\hline Percentage of cases with an antibiotic & $12.73 \%$ & $14 / 110$ \\
\hline Percentage of cases with an injection & $62.72 \%$ & $69 / 110$ \\
\hline \multirow{2}{*}{ Percentage of drugs from essential medicines list } & $\mathrm{WHO}^{13}$ & $200 / 300$ \\
\hline & NLEM $^{14}$ & $265 / 300$ \\
\hline
\end{tabular}

\section{DISCUSSION}

In this study, the majority of patients were between the ages of 6-15years and a female predominance of $55.5 \%$ was seen. These findings are comparable to a similar study completed by Rani UD et al, in Karnataka, India where majority of cases were in the 6-10years age group and a female predominance of $51.5 \%$ was also seen. ${ }^{9}$

When it comes to DF management, WHO states that there is no specific treatment and that supportive measures in maintaining body fluid volume is critical. Intravenous rehydration is the initial therapy for DF which can reduce case fatality to less than $1 \%$ of severe cases. ${ }^{15}$ In this study, all cases received IV Fluids and the commonly preferred IVF was normal saline. In the study by Rani DU et al, majority of their cases received $1 / 2$ DNS $(60.3 \%)$ and in a similar study done by Ghazala $\mathrm{D}$ et al, majority received Ringer's lactate $(41.8 \%)$. When choosing an IVF, the most commonly used is normal saline with Ringer's lactate being a preferable alternative. ${ }^{16}$ Symptomatic management was administered with majority of patients receiving antipyretics (90\%), antiulcer agents (88.18\%) and antiemetics $(70 \%)$. This was similar to the findings of another study where $100 \%$ cases received antipyretics, $94.1 \%$ received antiulcer agents and $79.4 \%$ received antiemetics. $^{9}$

WHO developed core drug use indicators with an aim to evaluate the medicines provided to a population. ${ }^{12}$ These indicators measure the performance of health care providers related to the appropriate use of drugs. ${ }^{17}$

\section{The average number of drugs per prescription}

In this study, the average number of drugs per prescription was $2.7 \pm 0.8$ compared to another similar study which was $3.8 \pm 1.1 .^{9}$ This indicator helps in determining polymedication which is a major factor contributing to adverse drug reactions, drug-drug interactions, non-compliance and increased cost for patients. WHO recommends the average number to be less than $2 .^{12,17}$

\section{Percentage of drugs prescribed by a generic name}

In this study, the percentage of drugs prescribed by a generic name was $7.33 \%$ which was similar to the study done by Rani UD et al. Generic drug prescriptions should be increased as it makes it easier for prescribers, dispensers and patients to identify drugs. It also controls drug costs in health service. ${ }^{12}$

\section{Percentage of encounters with an antibiotic prescribed}

Many antibiotics are unnecessarily prescribed for viral infections which contributes to bacterial dissemination and resistance. ${ }^{12,18}$ In this study, $12.73 \%$ of cases received antibiotics. In the study done by Rani UD et al, $48.5 \%$ received antibiotics. The percentage is quite lower in this study and may be due to a strict antibiotic policy which is followed at RRMCH.

\section{Percentage of encounters prescribed with injectable drugs}

About $62 \%$ of cases were administered drugs through the parenteral route in this study. WHO recommends lesser use of injections since it helps in reducing cost of treatment however the parenteral route of administration is justified in dengue patient due to the presence of gastrointestinal disturbances like nausea and vomiting. ${ }^{9}$

\section{Percentage of drugs prescribed from an essential medicines list}

By prescribing from the essential medicines list formulated by regulatory bodies, it guarantees the easy availability of treatment for principal diseases of a specific population at all times. ${ }^{12}$ In this study, $66.7 \%$ of drugs were from the WHO 20 ${ }^{\text {th }}$ Essential Medicines List 2017 and $88.3 \%$ were from National List of Essential Medicines of India 2015.

\section{CONCLUSION}

Drug utilization studies help in establishing proper treatment protocols for diseases. With the increasing incidence of DF, the demand for a more specific treatment protocol is needed. Results from this study show that the mainstay of treatment for DF in a paediatric population is with supportive and symptomatic measures in the form of fluid management, antipyretics, antiulcer agents and 
antiemetics. Also, majority of drugs prescribed are from essential medicine lists which attributes to the rationality of drug use and the use of antibiotics was very minimal. Limitations to this study include a small sample size achieved during the study period. Cost and adverse drug reactions were not analysed in this study.

\section{ACKNOWLEDGEMENTS}

Authors would like to thank the faculty and staff of Department of Paediatrics and Pharmacology of RajaRajeswari Medical College and Hospital for their help and guidance throughout this study.

Funding: No funding sources Conflict of interest: None declared

Ethical approval: The study was approved by the Institutional Ethics Committee

\section{REFERENCES}

1. World Health Organization. Dengue and Severe Dengue Fact sheet. Available at: http://www.who.int/mediacentre/factsheets/fs117/en/.

2. Azeredo EL, Monteiro RQ, de-Oliveira Pinto LM. Thrombocytopenia in dengue: interrelationship between virus and the imbalance between coagulation and fibrinolysis and inflammatory mediators. Mediators Inflammation. 2015;2015.

3. Selvan T, Nagaraj MV, Saravanan P, Somashekar. A study of clinical profile of dengue fever in children. Int J Contemp Pediatr. 2017 Feb 22;4(2):534-7.

4. Mutheneni SR, Morse AP, Caminade C, Upadhyayula SM. Dengue burden in India: recent trends and importance of climatic parameters. Emerging Microbes Infections. 2017 Aug;6(8):e70.

5. Dutta S, Beg MA, Bawa S, Anjoom M, Vishal S. Study of drug prescribing pattern in dengue patients in a tertiary care hospital: a tool to teach clinical pharmacology. J Drug Delivery Therapeutics. 2015 March;5(2):73-6.

6. Bandyopadhyay B, Bhattacharyya I, Adhikary S, Konar J, Dawar N, Sarkar J, et al. A comprehensive study on the 2012 dengue fever outbreak in Kolkata, India. ISRN Virol. 2013 Aug 7;2013.

7. Pancharoen $C$, Thisyakorn U. Dengue virus infection during infancy. Trans R Soc Trop Med Hyg. 2001;95(3):307-8.

8. Ghazala Z, Anuradha HV, Shivamurthy MC. Pattern of management and outcome of dengue fever in pediatric in-patients in a tertiary care hospital: a prospective observational study. Int $\mathrm{J}$ Basic Clin Pharmacol. 2014;3(3):534-8.

9. Rani U, Kamath S, Varun HV, Aithal S, Patil U. Prescribing patterns in dengue fever in paediatric patients in a tertiary care hospital: a retrospective cross sectional study. Int $J$ Pharm Sci Rev Res. 2014;24(2):112-18.

10. Vaddadi S, Vaddadi RS. Dengue fever: a review article. $\mathrm{J}$ of Evolution of Med and Dent Sci. 2015;4(29):5048-58.

11. Lee TH, Wong JG, Leo YS, Thein TL, Ng EL, Lee LK, et al. Potential harm of prophylactic platelet transfusion in adult dengue patients. PLoS Neglected Tropical Diseases. 2016 Mar 25;10(3):e0004576.

12. Aravamuthan A, Arputhavanan M, Subramaniam K. Assessment of current prescribing practices using World Health Organization core drug use and complementary indicators in selected rural community pharmacies in Southern India. J Pharmaceut Policy Practice. 2017 Dec;10(1):1.

13. WHO 20th Essential Medicines List, 2017, 1-62. Available http://www.who.int/medicines/news/2017/20th_essen tial_med-list/en/.

14. National List of Essential Medicines of India. 2015, 1$117 . \quad$ Available at: http://cdsco.nic.in/WriteReadData/NLEM2015/NLEM,\%202015.pdf.

15. Soegijanto S. The Monthly changing of the lowest population dengue virus infection in patient at Soerya Hospital Sidoarjo In 00. Indonesian J Tropical Infectious Dis. 2015 May 27;2(1):20-4.

16. Hung NT. Fluid management for dengue in children. Paediatr Int Child Health. 2012 May 1;32(sup1):3942.

17. World Health Organization. How to investigate drug use in Health Facilities: selected drug use indicators. Geneva.1993. Available at: http://apps.who.int/medicinedocs/en/d/Js2289e/

18. Basha SA, Sathiswara B, Siddarama R. Prescribing pattern of drugs in pediatric department in a tertiary care teaching hospital. World J Pharmacy Pharmaceutical Sci. 2018;7(2):1129-36.

Cite this article as: Rammohan $\mathrm{S}$, Bhandare B, Adarsh E, Satyanarayana V. The prescribing pattern for the management of dengue fever in pediatric patients of a tertiary care hospital: an observational study. Int J Basic Clin Pharmacol 2018;7:2384-8. 